\title{
PROVA ONLINE: SISTEMA DE GERAÇÃO AUTOMÁTICA DE AVALIAÇÕES ONLINE
}

JUAZEIRO DO NORTE/CE MAIO/2018

\author{
João Paulo Vital Santos - FAP - JOAOPAULO@FAPCE.EDU.BR \\ Roberto Michelan - FAP - ROBERTO.MICHELAN@FAPCE.EDU.BR \\ Lana Paula Crivelaro Monteiro de Almeida - FAP - lanacriv@terra.com.br
}

Tipo: Relato de Experiência Inovadora (EI)

Categoria: Métodos e Tecnologias

Setor Educacional: EDUCAÇÃO SUPERIOR

\begin{abstract}
RESUMO
A tarefa essencial de avaliar os alunos ficou mais complexa com o advento da moderna Educação a Distância (EAD). Os professores tiveram suas necessidades de atualização multiplicadas e agora têm de coordenar o ensino para um número cada vez maior de aprendizes. Com vistas a auxiliar o docente em seu plano avaliativo, foram criadas diversas ferramentas de geração automática de avaliações, baseadas, essencialmente, em provas eletrônicas geradas a partir de um banco de questões. Este artigo consiste na análise de algumas destas ferramentas, elencando suas principais funcionalidades $e$ limitações, e apresenta a criação de outra ferramenta, a saber, o Prova Online. Este software atende aos principais requisitos deste tipo de programa e além de permitir ao avaliador (professor ou instituição de ensino) ter controle sobre sua própria base de conhecimento, possibilita também que se criem outros tipos de provas, nem sempre suportadas pelos softwares de mercado, como o vestibular eletrônico, por exemplo.
\end{abstract}

Palavras-chave: Avaliação, Educação a Distância, Professor, Banco de Questões. 


\section{INTRODUÇÃO}

As Tecnologias da Informação e Comunicação (TIC) têm revolucionado o cenário da educação no Brasil e por todo o mundo e com isso ocorrem as possibilidades de redução de custos e de melhorias significativas no serviço educacional que justificam seu uso, cada vez mais frequente, por parte de diversas Instituições de Ensino (WOLYNEC, 2003), dentre elas a modalidade de ofertas na Educação a Distância (EAD) inclue-se neste cenário.

A EAD tem sido agente de transformação do processo de ensino e aprendizagem, fator este impulsionador de uma necessidade de adaptação constante, não apenas por parte dos alunos, mas principalmente, dos professores (MACHADO; MORAES, 2015). os quais detêm a maior necessidade de se adequarem às novas possibilidades e formatos desta modalidade de ensino uma vez que a sala de aula nesta modalidade torna-se expandida e o professor assume a figura do moderador que agora coordena e motiva um grupo quase ilimitado e heterogêneo de aprendizes (MACHADO; MORAES, 2015). Nesse novo cenário, ele deve não apenas expor seu conhecimento, mas também deve ser capaz de transformar o aprendiz em um estudante autônomo.

Tais transformações, porém, não eximiram o professor de suas tarefas educacionais antes realizadas, mas acabou-se por tornar tais atividades ainda mais complexas, principalmente no que se refere as questões avaliativas.Os docentes da modalidade a distância têm agora que reinventar sua maneira de 'dar aula', uma vez que outras necessidades surgiram e lhes obrigaram a se adaptar" (MACHADO; MORAES, 2015). E é principalmente essa adaptação e reinvenção constantes que desafiam o professor.

Qualquer mecanismo que surja com a proposta de auxiliá-lo em seu trabalho não só é bem vindo como também deve ser incentivado. Como exemplo de iniciativas que visam ajudar o professor em suas tarefas, e tendo por base o problema envolvendo as avaliações, foram criadas várias ferramentas de geração automática de provas, algumas online, outras não. O principal objetivo destas ferramentas é possibilitar que o docente desenvolva e corrija inúmeras provas com maior eficiência, otimizando seu tempo para outras tarefas do processo ensino e aprendizagem (KAMPFF; ALVES, 2010). Tais ferramentas são um subproduto das novas tecnologias que surgiram para apoiar 0 trabalho na sala de aula e além dela.

Várias ferramentas disponíveis no mercado propõem-se a auxiliar no processo avaliativo dos alunos. A maior parte delas utiliza-se da ideia, aparentemente simples, de criar e manter uma base de questões que são usadas para gerar as provas. Esta abordagem 
parece ser bem comum em se tratando de educação a distância (LITTO; FORMIGA, 2009). A maior parte das ferramentas estão disponíveis comercialmente e, salvo raras exceções, não permitem ao professor a liberdade de manter sua própria base de conhecimento. Por base de conhecimento entende-se o armazenamento em banco de dados das questões de diversas disciplinas ministradas pelo professor. Muitos desses softwares, por exemplo, oferecem bases para nichos específicos, como o Ensino Médio, não abrangendo matérias do ensino superior e técnico.

Outro ponto interessante quanto às atuais ferramentas, diz respeito aos tipos de provas que permite serem criadas; ou ainda, aos cenários em que podem ser utilizadas. Um exemplo comum de avaliação, que requer configurações nem sempre suportadas, é o vestibular eletrônico, modalidade que tem crescido entre as instituições de ensino superior. O conhecimento usado para tal, porém, pode ser uma base de questões do ensino médio bastante comum, mas pouco usada com essa finalidade. As ferramentas que permitem esse tipo de uso requerem, em geral, um alto valor de investimento.

Neste contexto pareceu-nos útil desenvolver uma ferramenta que dê ao avaliador (professor ou mesmo uma instituição de ensino) a possibilidade de manter sua própria base de conhecimento (questões) podendo usá-la para finalidades avaliativas variadas, que vão desde a geração de provas para avaliar o desempenho de um aluno em um curso à aplicação de um processo seletivo, como um vestibular eletrônico agendado. Uma ferramenta como essa abre a possibilidade da criação de vários nichos do conhecimento e ainda estende os usos que se pode fazer de uma mesma base de questões.

Este trabalho, portanto, consiste de uma análise qualitativa de algumas das ferramentas de geração automática de avaliações disponíveis no mercado observando suas carências e propondo outras funcionalidades de auxílio. $\mathrm{O}$ objetivo foi criar um protótipo de aplicação que supra algumas das atuais limitações e se adéque melhor às necessidades de vários professores de disciplinas EAD e presenciais tendo por base a manutenção, por parte do detentor do conhecimento.

\section{O processo de Avaliação}

Avaliar o aprendizado do aluno é tarefa fundamental na agenda de qualquer professor, seja utilizando o método tradicional com papel e caneta, seja fazendo uso de computadores com softwares especializados. A avaliação é necessária e independe da modalidade de ensino escolhida. 
A preocupação em torno do assunto, porém, não é nova e tem sido exaustivamente discutida principalmente com a chegada da educação a distância. Esta tem impulsionado a busca por novas maneiras não tradicionais de medir o conhecimento do aprendiz, conforme atesta Litto e Formiga (2015):

A avaliação da aprendizagem é uma preocupação do docente, o que se expressa pelas inúmeras publicações nas áreas que visam aperfeiçoar e enriquecer as ferramentas de comunicação e interação, em vista de monitorar os aspectos informais do desempenho do aluno.

As críticas aos métodos tradicionais (avaliações baseadas em um questionário) tornaram-se frequentes nos debates envolvendo o tema das avaliações, de modo que o assunto tornou-se bastante controverso. Em se tratando de EAD, questiona-se, principalmente, o fato de o aluno nem sempre estar ao alcance do professor o que abre margem para fraudes nas resoluções (SILVA et al., 2015). Talvez seja essa a preocupação por traz da legislação brasileira que exige, para os cursos de EAD, a realização de provas presenciais em um pólo de apoio da instituição (Resolução CNE/CES no 1, de 8 de Junho de 2007). Já os que advogam que essa exigência é desnecessária argumentam que uma nova modalidade de ensino não deve estar limitada às práticas de outra, a saber, o ensino presencial (LITTO; FORMIGA, 2009).

Seja qual for o ponto de vista nesta questão, convém frisar que o assunto das avaliações não é controverso apenas para a educação a distância, mas também para o ensino tradicional. De forma que nem sempre se evolui ponderando sobre o assunto, uma vez que, no fim das contas, o valor da avaliação é subjetivo e depende, muitas vezes, dos critérios do avaliador (MACHADO; MOARES, 2015).

Para se avançar no assunto, adotou-se a postura de analisar e classificar os métodos avaliativos, observando suas particularidades e aplicações. Nesse ponto, utilizando os termos clássicos (LITTO; FORMIGA, 2009), as avaliações podem ser classificadas em:

- Diagnóstica: A qual objetiva identificar as carências do aluno. Como o próprio nome indica, seu resultado funciona como um diagnóstico, indicando ao avaliador em que ponto o aprendiz está em relação ao conhecimento avaliado.

- Somativa: Geralmente utilizada na forma de uma única avaliação por disciplina e quase sempre ao final do período de estudos. Permite atribuir apenas uma nota a todo o processo de aprendizado que o aluno teve no decorrer do curso.

- Formativa: A qual é a mais indicada para a educação a distância. Nela se evidencia uma preocupação real e mais presente, por parte do professor, de que 
- aluno esteja acompanhando os assuntos estudados. Várias atividades avaliativas são utilizadas para mostrar as carências do aprendizado, na expectativa de corrigi-las a tempo.

Essa classificação permite entender os momentos em que as avaliações são aplicáveis, de modo que ela aparece antes, durante e depois da aprendizagem fornecendo informações úteis para auxílio do professor.

\section{Avaliação Online}

Uma das modalidades de avaliação, utilizadas hoje principalmente em educação a distância, é a avaliação online. Como o próprio nome sugere consiste na exposição das questões através de um sistema baseado na web. É uma abordagem bastante comum e diversas ferramentas já foram propostas para utilização (CARDOSO, 2001).

Seu uso permite a identificação de deficiências dos alunos por meio da aplicação de testes e exercícios, fornecendo "resposta imediata sobre o progresso do entendimento dos estudantes [ajudando] tanto professores quanto alunos a tomarem ações em um tempo adequado, antes que seja muito tarde" (CARDOSO, 2001).

Como todo recurso oriundo das Tecnologias da Informação e Comunicação (TIC) possui vantagens e desvantagens sendo recomendado alinhar seu uso com os objetivos do plano avaliativo do professor. Cardoso (2001) cita várias vantagens desse tipo de avaliação, dentre as quais é possível mencionar:

- Mais fácil e rápido para os estudantes responderem;

- Fácil de distribuir, coletar e analisar os dados;

- Possibilita o julgamento objetivo e rápido;

- Submissão dos resultados a tratamento estatístico de forma mais automatizada;

- Fácil utilização;

- Não depende de aspectos temporais.

Como desvantagens, também citadas pelo mesmo autor:

- Risco de haver compartilhamento de respostas entre alunos;

- Não avaliam as habilidades de expressão;

- Restringem as respostas dos alunos;

- É necessário que todo o público envolvido tenha acesso à Internet;

- É necessário material digital. 
Para o risco de compartilhamento de informações tem sido proposto, para a aplicação das provas (no pólo de apoio presencial), a presença de um fiscal que acompanhe os estudantes durante a realização dos testes (CARDOSO, 2001), embora nem sempre isso seja possível em todos os momentos do ensino a distância. Para as demais desvantagens, convém dizer que, independentemente das limitações dessa modalidade de avaliação, tem sido constante o consenso entre os teóricos de que é importante diversificar as técnicas e os instrumentos utilizados para medir a aprendizagem dos alunos (MACHADO; MORAES, 2015).

Em EAD, essas avaliações quase sempre consistem de questões objetivas e dissertativas, com destaque para a diferença entre o tempo de correção necessário para os dois tipos, conforme menciona Machado e Moraes (2015). Nas perguntas objetivas os alunos recebem sua nota logo após a realização das atividades, visto que o software [...] realiza imediatamente a correção a partir de um gabarito. As dissertativas por sua vez são corrigidas pelos professores tutores.

Um ponto importante a se considerar sobre as avaliações eletrônicas é a necessidade de se monitorar as ações do participante, uma vez que questionamentos poderão surgir acerca das questões ou da interação com a prova. Sendo assim, mecanismos de auditoria do processo são extremamente necessários.

\section{Proposta do trabalho}

Depois da análise de algumas das ferramentas de geração automática de provas, foi desenvolvido um protótipo de aplicação, denominado Prova Online, dividido em três ambientes para gestão da ferramenta (Administrador, Conteudista, Avaliador) e a seção onde se realizam as provas. O Prova Online foi assim dividido para permitir seu uso tanto por instituições de ensino - que podem envolver várias pessoas ao sistema, dividindo tarefas - como por professores individualmente - que terão acesso a todas as funcionalidades.

O melhor modo de usar o Prova Online é compreendido como aquele em que a própria instituição de ensino utiliza a aplicação para manter sua própria base de conhecimento. Neste cenário, todos os professores alimentam o banco de dados de questões que poderia ser reutilizado por outros professores que ingressarem no futuro. Assim sendo, o conhecimento ficaria com a instituição, trabalhando a seu favor.

Fontes para as questões não faltam, pois além dos professores (que são convidados a manter suas questões na ferramenta), podem ser utilizadas todas as questões de 
processos seletivos (vestibulares) e de simulados já realizados, além de provas anteriores de outros professores.

O Prova Online foi pensado de modo a criar ambientes ou contextos dentro da aplicação, o que permite mais organização e divisão de foco. Por exemplo, uma mesma instituição pode querer usar o software para gerar suas provas de vestibular eletrônico e ao mesmo tempo desejar que seus professores utilizem a ferramenta em sala de aula. Para dividir as provas que dizem respeito aos professores das que são de responsabilidade da secretaria, pode-se criar o ambiente "sala de aula", para uso dos docentes e o ambiente "secretaria" para uso do setor administrativo.

Associado ao ambiente há o conceito de encapsulamento (público e privado). Pode-se querer, por exemplo, que todos os usuários do ambiente "secretaria" visualizem as provas geradas no âmbito da secretaria (as provas de vestibular, por exemplo). Mas comportamento semelhante pode não ser desejado para o ambiente "sala de aula" no qual se espera que cada professor gerencie suas próprias provas, sem interferir ou visualizar as avaliações de outros professores. Com base nisso, o ambiente "secretaria" é público (pois permite que todas as secretárias compartilhem o acesso às mesmas provas) e o ambiente "sala de aula" é privado (por limitar o acesso às provas somente ao professor que as criou).

Quanto às provas, o Prova Online baseia-se na ideia de que, utilizando a mesma base de questões, podem ser criados diferentes tipos de prova, as quais serão diferenciadas apenas pelas regras aplicadas a elas (regras de acesso, tempo, pesos das questões, etc.). Isto possibilita que avaliações como simulados, vestibulares, exercícios ou a prova final de uma disciplina, sejam geradas a partir da mesma base de conhecimento.

A vantagem de poder gerir sua própria base de questões é que, para algumas instituições, pode não ser interessante usar em seus processos seletivos questões compartilhadas ou advindas de outros vestibulares. As ferramentas pagas disponíveis no mercado, que já oferecem inúmeras questões, têm essa desvantagem quando se trata desse tipo de prova (embora haja ferramentas que permitem a inclusão de questões da própria instituição), mas seu uso pode ser bastante dispendioso em longo prazo.

Adicione-se também, a vantagem de poder manter questões não abrangidas em nenhum banco de dados disponível como serviço pelas ferramentas de mercado. Por exemplo, é possível encontrar questões do ensino médio com facilidade, mas se o que se deseja são questões de computação gráfica para o curso de Sistemas de Informação, 
por exemplo, não se encontra tão facilmente. Mesmo que alguns ofereçam questões do ENADE (que são de disciplinas do ensino superior), imagina-se que o melhor e mais interessante é utilizar o conhecimento da própria instituição, que já faz uso dessas questões por meio dos seus professores. Sem falar em disciplinas do ensino técnico, que não são oferecidas em nenhum banco de questões comercial.

Outra funcionalidade pensada para o Prova Online, e considerada de grande importância, é a capacidade de visualizar, por meio de logs de eventos, as ações de todos os usuários. O recurso (aqui chamado de auditoria) é essencial uma vez que, em se tratando de provas, é comum serem enviados recursos com questionamentos sobre a avaliação e/ou sobre sua aplicação. Nestas situações, os logs dos eventos serão muito úteis para esclarecer fatos e auxiliar na tomada de decisões.

\section{Segurança do Processo}

Antes de concluir a seção das provas convém mencionar questões de segurança envolvendo as avaliações. Durante a realização, as questões marcadas são informadas, via Ajax, ao servidor no exato momento em que o participante marca as alternativas. De forma que se o mesmo abandonar a prova e retornar depois, a avaliação continuará a partir da última questão respondida. No mesmo cenário, se ao retornar o tempo de prova já tiver sido expirado o alerta de finalização descrito anteriormente será automaticamente exibido, podendo o tempo ser estendido ou não pelo fiscal de sala (para as provas privadas).

De forma semelhante ao envio das alternativas marcadas, o status "visualizada" é informado, para cada questão que o participante visualizar, mesmo que não a responda. A ideia é impedir que no futuro, o participante venha a realizar outra prova com questões que já teve contato anteriormente. Dentro do Prova Online, os participantes só respondem a uma questão uma única vez, independente da prova que venha a fazer.

\section{CONSIDERAÇÕES FINAIS}

Criar e corrigir avaliações são tarefas que exigem muito dos professores. Especialmente no cenário da educação a distância no qual o número de alunos pode ser significativamente grande. Agravando este problema está também a necessidade de extrair informações estatísticas dos resultados das provas que deverão ajudar o professor a identificar carências de aprendizado e outros insights úteis para trabalhar o crescimento de seus alunos. Estas informações não são facilmente obtidas utilizando-se os métodos tradicionais de avaliação (em papel). 
Uma ferramenta muito útil nestes casos é a avaliação online, que pode diminuir os tempos de confecção e de correção das provas. Pode também extrair facilmente informações relevantes com base nos dados coletados.

Embora existam várias ferramentas que se propõem a gerar avaliações automáticas, nem sempre é possível fazer o uso que se deseja das provas ou ter o controle sobre sua própria base de conhecimento. Algumas até oferecem vastos bancos de questões e permitem que se incluam novas, mas exigem, geralmente, um alto custo de manutenção.

Uma limitação presente diz respeito a poder utilizar as avaliações como vestibular eletrônico, uma modalidade que tem crescido nos últimos anos. Várias instituições de ensino têm vasto material que poderia ser utilizado a seu favor na geração de seus processos seletivos, e isto sem cobrar pelo uso das questões, como fazem algumas ferramentas do mercado.

O Prova Online foi proposto para permitir a criação de avaliações online que suportem diversos cenários nos quais estas podem ser utilizadas, tais como: listas de exercícios, simulados, avaliações finais de uma disciplina e até mesmo um vestibular eletrônico. Isto é possível graças à criação de provas com várias regras associadas a elas.

A ferramenta também permite ao avaliador (que pode ser o professor ou outro usuário de uma instituição de ensino) manter sua própria base de conhecimento, possibilitando a criação de inúmeras questões de matérias não abrangidas nos serviços pagos. Acrescente-se o fato de o Prova Online ser uma alternativa de baixo custo quando se consideram os custos envolvidos no uso de ferramentas pagas, além de poder ser explorado comercialmente.

Além das diversas possibilidades apresentadas, o Prova Online permite que sejam extraídas, por meio de relatórios, informações úteis para o controle do avaliador, sempre focando em facilitar o seu trabalho em sala de aula.

Apesar dos objetivos do projeto terem sido alcançados, o software desenvolvido ainda carece de outras funcionalidades para suprir o que algumas ferramentas de mercado já oferecem, como por exemplo, os vários tipos de questões (verdadeiro ou falso, com lacunas, associativas, etc.) e o recurso de auto-avaliação que permite aos participantes criarem suas próprias provas, auxiliando em seus estudos. Estas melhorias podem ser construídas em trabalhos futuros sobre o Prova Online. 


\section{REFERÊNCIAS}

BRAGA, P. C. et al. 2017. Vestibular Eletrônico por meio da Plataforma Blackboard: A experiência do IESB. Disponível em: . Acesso em: 10 mar. 2017.

CARDOSO, R. F. AvalWeb : sistema interativo para gerência de questões e aplicação de avaliações na web. Porto Alegre: UFRGS, 2001. Dissertação (Mestrado em Ciências da Computação) - Programa de Pós-Graduação em Computação, Universidade Federal do Rio Grande do Sul, 2001.

KENSKI, V. M. Educação e Tecnologias: o novo ritmo da informação. 3. ed. Campinas: Papirus, 2007.

LITTO, F. M; FORMIGA, M. Educação a Distância: o estado da arte. São Paulo: Pearson Education do Brasil, 2009.

MACHADO, D. P; MORAES, M. G. S. Educação a Distância: Fundamentos, Tecnologias, Estrutura e Processo de Ensino e Aprendizagem. São Paulo: Érica, 2015.

MEDEIROS, A. R. M; MACHIORO, G. F. AvaliaNet: Geração Automática de Provas e Exercícios. Disponível em: . Acesso em: 10 mar. 2017.

SILVA, T. E. V. et al. Avaliação em EAD: Teoria e prática. Recife: Imprima, 2015. 